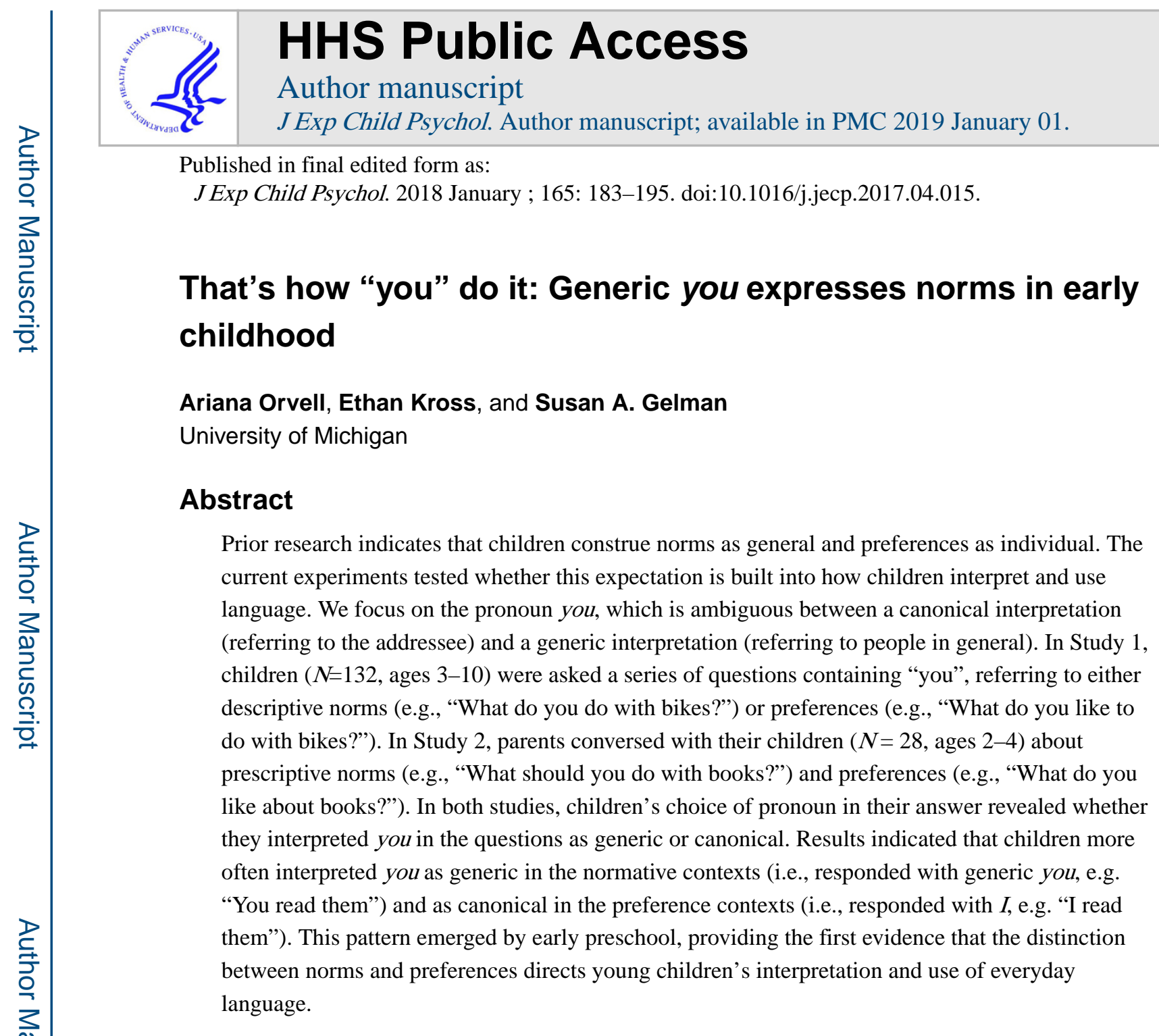

\title{
Keywords
}

Norms; language; generics; language acquisition

\begin{abstract}
An important feature of norms is that they are general: "Thou shalt not kill" did not just apply to Moses, and "Drive on the right-hand side of the road" does not just apply to those who feel like doing so. Norms derive their power by providing rules of conduct and expected regularities of behavior that apply broadly, allowing individuals to coordinate their actions with one another. The classic tension between an individual's wishes and what is best for the group can be managed by an expectation that certain rules extend beyond the person who creates them, and may take precedence over personal desires.
\end{abstract}

Send correspondence to: A. Orvell at aorvell@umich.edu or S.A. Gelman at gelman@umich.edu.

Publisher's Disclaimer: This is a PDF file of an unedited manuscript that has been accepted for publication. As a service to our customers we are providing this early version of the manuscript. The manuscript will undergo copyediting, typesetting, and review of the resulting proof before it is published in its final citable form. Please note that during the production process errors may be discovered which could affect the content, and all legal disclaimers that apply to the journal pertain. 
Here we suggest that this expectation of norms as general is a foundational principle that is built into young children's interpretation and use of language. We examine this idea by focusing on generic "you," a ubiquitous but understudied expression that refers broadly to people in general (e.g., "You don't eat ice cream with your fingers"; "You need to be 21 to drink"; "You only live once"). Specifically, we propose that early in development, children honor a tight link between norms and group-level representations, and this link is expressed in language via generic you.

\section{Groups and norms}

Norms are fundamentally broad in scope, applying generally across individuals (Mulkay, 1976). They may be descriptive, referring to regularities of human behavior, or prescriptive, expressing expectations for how people should act (Cialdini \& Trost, 1998). Descriptive norms characterize behaviors that are likely to be exhibited by members of the group, thus providing insights into how people typically act in similar situations (Pepitone, 1976 in Cialdini \& Trost, 1988; Cialdini, Reno \& Kallgren, 1991). In contrast, prescriptive norms convey more explicit expectations for acceptable (vs. unacceptable) behavior. Although descriptive and prescriptive norms can be distinguished in these ways, recent work suggests that they are often conflated in how people reason. In this vein, descriptive norms inform people's expectations of what should be (Tworek \& Cimpian, 2016; Bear \& Knobe, 2016). For example, children 4-6 years of age judged individuals who violated a group regularity (e.g., listening to a different type of music than others in their group) as having done something wrong (Roberts, Gelman, \& Ho, in press). For these reasons, in this paper we use "norms" to include both regularities and valued expectations of behavior that are shared among members of groups.

Children grasp the generality of norms from an early age (Kalish, 2012; Göckeritz, Schmidt, \& Tomasello, 2014; Rakoczy \& Schmidt, 2013; Rhodes, 2014). For example, when reasoning about third-party vignettes, preschool children generalize behaviors motivated by normative obligations from one individual to another person of the same social category (Kalish, 2013). Moreover, in face-to-face interactions, 2- to 3-year-olds protest and criticize another child who violates the rules of an invented game, indicating that they expect the rules to apply not only to those who initially invented the game but also to newcomers who are playing the game for the first time (Rakoczy \& Schmidt, 2013; Rakoczy, Warneken, \& Tomasello, 2008, 2009).

Norms are furthermore distinctive in their generality: whereas norms are assumed to be general, preferences are understood to vary from person to person. By 18 months of age, children understand that one person's likes and dislikes are not necessarily shared by others (Repacholi \& Gopnik, 1997; Wellman \& Liu, 2004), and preschool children do not generalize behaviors motivated by psychological states from one individual to another person of the same social category (Kalish, 2013). Indeed, the very same content (food selection) can be construed as normative or not, depending on whether it is framed as a group-linked behavior or an individually-linked preference (cf. Repacholi \& Gopnik, 1997, with Roberts et al., in press). 
The link between norms and groups is also bidirectional: Children not only expect norms to apply generally, they also expect group behaviors to be normatively appropriate. As noted earlier, Roberts, Gelman, and Ho (in press) found that properties attributed to contrasting novel groups (Hibbles and Glerks) were viewed normatively, leading to negative evaluations of those who failed to conform to the behavior typical of the group. In contrast, in a control condition in which properties were attributed to contrasting individuals rather than contrasting groups, children did not have a negative evaluation of non-conforming individuals.

\section{Nouns with a generic reading}

How do people communicate the link between groups and norms in language? To answer this question, we first need to consider how languages express concepts of groups. One common way of referring to categories or groups is with full noun phrases (e.g., "dogs" in the statement, " $\operatorname{Dog} s$ are friendly"). This contrasts with using nouns to make specific reference to an individual or individuals within a group (e.g., "dogs" in the statement, "These $\operatorname{dog}_{s}$ are friendly"). Henceforth we refer to the former as "generic nouns", for ease of expression, although it should be noted that whether a noun is specific or generic is not determined by the noun phrase per se but rather its context of use (Gelman \& Raman, 2003; Papafragou, 1996). Generic nouns are universally available in the world's languages (Carlson \& Pelletier, 1995). They express conceptually central generalizations (Cimpian \& Markman, 2009; Hollander, Gelman, \& Raman, 2009) and imply that a category is homogeneous, inductively rich, and stable over time and contexts (Gelman, Ware, \& Kleinberg, 2010; Rhodes, Leslie, Tworek, 2012). They are also common in the speech that adults direct toward children (Gelman, Coley, Rosengren, Hartman, \& Pappas, 1998), appear frequently in children's instructional books (Gelman, Ware, Manczak, \& Graham, 2013), and are acquired early in development, by about $2 \frac{1}{2}$ years of age (Gelman, Goetz, Sarnecka, \& Flukes, 2008; Graham, Gelman, \& Clarke, 2016).

Importantly, there are several indications that generic nouns may imply norms. Adults judge certain generics to be not just general but also proper and natural (e.g., "Dogs are 4-legged" implies that dogs should be 4-legged; Prasada \& Dillingham, 2006, 2009). Similarly, some generics endorsed by adults express norms more than epistemic truths. For example, statements such as "Boys don't cry" or "Scientists care only about the truth" may not be descriptively accurate (e.g., in fact most boys do cry, at least sometimes, and some scientists care more about tenure or lucrative patents than the truth), but adults use them to express group-relevant norms (Knobe, Prasada, \& Newman, 2013; Leslie, 2015; Wodak, Leslie, \& Rhodes, 2015).

These findings suggest that at least certain generic nouns are used to convey normative concepts about groups, but such findings are currently limited in scope to particular content (e.g., boys being stoic) and thus may reflect learned beliefs about particular features that are associated with categories rather than a more general link between groups and norms. They thus raise the question of whether there is an expectation that generic language links to norms more broadly, beyond the particular categories and properties that have been studied to date. 


\section{Generic 'you'}

The second-person pronoun you provides a mechanism for examining more directly the link between normative reasoning and generics. Whereas canonically you refers specifically to one's addressee (e.g., "You gave a great talk!"), you also has a generic interpretation, referring to 'one' or people in general (e.g., "You win some, you lose some"; Berry, 2009; Myers \& Lampropoulou, 2012; Wales, 1996). For ease of expression, we refer to generic uses of you as "generic you", although as with generic nouns, the generic reading is not located in a distinctive form of the word but rather its context of use. Importantly, generic you expresses generalizations that extend beyond specific groups (e.g., boys, scientists) to people more broadly. Of particular relevance to the present discussion, qualitative linguistic analyses suggest that generic you may be used to express norms, rules, or moral teachings (Bolinger, 1979; Hyman Staels, 2004; Laberge \& Sankoff, 1979; Pennycook, 1994).

A recent set of experiments with adults demonstrates that generic you is selectively elicited when talking about rules and norms (Orvell et al., 2017). Adult participants read a series of questions that referred to either norms (prescriptive: "What should you do with Xs?" or descriptive: "What do you do with Xs?") or preferences ("What do you like to do with Xs?"), where X was a common object (e.g., lamps). These questions were all ambiguous, open to either a generic interpretation (e.g., "What should one do with Xs?") or a canonical interpretation (e.g., "What should [addressee's name] do with Xs?"). Participants' task was simply to write down a response to each question; responses were then coded for pronoun usage. Responses containing you (e.g., "You should turn them on") were coded as generic; those containing $I$ (e.g., "I like to turn them on") were coded as non-generic. Notably, results indicated that responses shifted markedly from generic in response to normative questions ("What should you do with TVs?", "What do you do with TVs?") to non-generic in response to non-normative questions ("What do you like to do with TVs?").

These data raise the question of whether children understand generic you as linked to norms early in development. Although personal pronouns are typically produced by age 2 years (Fenson et al., 1994), and children master their non-generic uses by age 3 years (OshimaTakane, Takane, \& Shultz, 1999), little is known regarding when and how generic you develops in childhood. Moreover, there are competing developmental predictions surrounding this issue.

On the one hand, given the canonical use of you as non-generic, and claims that children below 7-8 favor item-specific versus category representations (Fisher \& Sloutsky, 2005), young children may initially misinterpret generic uses of you as referring to the immediate context (i.e., the addressee(s)), or simply be confused as to when and why you is used generically versus specifically. In contrast, given children's early sensitivity to generic noun phrases (e.g., Cimpian \& Markman, 2008; Gelman \& Raman, 2003), and the relatively high rates of generic you in adult corpora, ostensibly including that of parents and teachers (Jensen, 2009; Myers \& Lampropoulou, 2012), it is also possible that the generic interpretation of you may emerge by preschool age. 
Two published papers provide intriguing hints to suggest that sensitivity to generic you may arise early in development. One case study of personal pronoun reversal in two Englishspeaking children parenthetically noted that both children produced generic you in their earliest productive speech (11-35 months; Evans \& Demuth, 2012). For example, at age 2 years 10 months, one child said, "That's how you make a square," which was coded as a generic use of you. Furthermore, an experimental study of 5-year-old German-speaking children found that children tended to express norms using generic language. However, here a variety of linguistic expressions constituted generic language, including any utterance that extended beyond the concrete "here-and-now," including "Marbles always go here," "It needs to be done this way," or "One must do it like this" (Göckeritz, Schmidt, \& Tomasello, 2014). Thus, more systematic data are needed to address children's understanding that you can be used in a generic sense, whether its use is favoured in normative contexts, and how usage of you compares for normative versus preference contexts.

\section{The Present Studies}

To our knowledge, the present research provides the first experimental tests of whether children early in development differentially link norms with generic language, and preferences with specific language, by examining children's interpretation and use of generic versus canonical you. We report two studies: Study 1 provides a controlled experimental task examining children's interpretation of you in response to questions that ask about either descriptive norms or preferences; Study 2 focuses on naturalistic parentchild conversations examining children's interpretation of you in questions that ask about either prescriptive norms or preferences. The pronoun you has three distinctive advantages for addressing this question. First, it permits a broader test than studies of generic noun phrases, as generic you applies to people in general (not just specific concepts, such as 'boys' or 'scientists'). Second, due to the ambiguity of the pronoun, we can test whether the very same word shifts interpretation based on its semantic context (normative vs. preference). And third, because you emerges early in development, it is plausibly a mechanism that even young children would be sensitive to.

\section{Study 1}

We hypothesized that children presented with you in questions regarding behavioral regularities—descriptive norms (e.g., "What do you do with Xs?")—would interpret the pronoun as generic, whereas children presented with you in the context of questions regarding preferences (e.g., "What do you like to do with Xs?") would interpret it as specific. Conventional interactions with artifacts are guided by norms and rules (Casler, Terziyan, \& Greene, 2009; Siegel \& Callanan, 2007). Thus, we expected that simply asking children what they do with various objects would lead them to draw on descriptive norms for behavior associated with each type of object. In contrast, we expected that asking children about their preferences would elicit personal opinions rather than broad norms. We included a wide age range of children (3-10 years of age), given the lack of available data to tell us when children would be sensitive to generic you. 


\section{Method}

Participants-Participants were 132 children ( 87 female). Data were collected from children in three age groups: 3 - to 4-year-olds: $n=50,32$ female, $M=3.91, S D=.58 ; 5$ - to 6-year-olds: $n=47,30$ female, $M=5.96, S D=.53$; 7- to 10-year-olds: $n=35,25$ female, $M$ $=8.81, S D=1.09$. Two children from the 3- to 4-year-old group did not complete the task and were dropped from the analyses. One participant completed the experiment twice; his second testing session was excluded from the analyses. All participants were recruited from a children's museum in a small Midwestern city.

Materials-Materials used during a brief warm-up activity included pictures of scenarios with common objects (e.g., flying airplane, dog chasing ball) and a puppet. Materials used during the experimental trials consisted of laminated $3^{\prime \prime} \times 4$ " pictures of six familiar objects (bike, crayons, ball, book, puzzle, TV). Each picture was presented by itself against a white background.

Procedure-Two experimenters administered the experiment at a table set up in the gallery of a children's science museum. Children participated individually. When parents and children approached the table, one experimenter obtained informed parental consent and permission to audio record the session while the other talked with the child to obtain child assent. The session began with one experimenter administering the protocol with the child while the other initiated the audio recording and wrote down participants' responses.

Experimenters took turns performing these roles.

Warm-up activity: First, children completed a short-warm activity during which they were introduced to a puppet. The purpose of the warm-up activity was to encourage children to use full sentences during the experimental trials to ensure that we would obtain codable responses (i.e., utterances with subject pronouns). The experimenter showed a picture to the puppet and asked him to describe what was happening in it. The puppet modeled answering in a full sentence (e.g., "The dog is chasing the ball"). The experimenter then provided reinforcement (e.g., "Right! The dog is chasing the ball. That was a great full sentence!"). Next, the experimenter asked the child to describe what was happening in a different picture. If the child used a full sentence, the experimenter provided positive reinforcement (e.g., "That's right; the airplane is in the sky. Great full sentence."); if the child did not provide a full sentence, the experimenter used the puppet to model one, and then asked the child to repeat it. Children completed three practice trials.

Main task: To signal that the experiment was beginning, the experimenter asked the child if they wanted to continue with a different game, and reassured them that there were no right or wrong answers. In the main task, children were asked a series of questions about six familiar objects (see Materials section, above). Piloting revealed that children were familiar with all of the objects. However, to ensure that children accurately identified the object in the picture, the experimenter asked the child to identify the item before asking each question. If the child did not provide an appropriate label (which very rarely happened), the experimenter identified the object for the child, and then asked them if they knew what it was. 
Once the child indicated that they were familiar with the object, the experimenter proceeded to the experimental question. Children were randomly assigned to one of two conditions, either "Norms" ( $n \mathrm{~s}=25$ [3-4 years], 24 [5-6 years], and 16 [7-10 years]) or "Preferences" $(n s=22$ [3-4 years], 23 [5-6 years], and 19 [7-10 years]). Random assignment to condition was determined before data collection, such that each participant's ID number was already associated with a condition when the child began the session.

Participants assigned to the "Rules" condition were asked, "What do you do with Xs (e.g., books)?" for each of the six objects. Children assigned to the "Preferences" condition were asked, "What do you like to do with Xs (e.g., books)?" for each of the six objects (emphases added here for clarity). The prompts were deliberately ambiguous such that a response with $I$ (e.g., "I bounce balls") would indicate that you was interpreted canonically (i.e., referring to the participant), whereas a response with you (e.g., "You bounce balls") would indicate that you was interpreted as generic (i.e., referring to people in general).

If the child did not respond to the question, the experimenter asked the question again. If the child responded but did not provide a pronoun in their response, the experimenter prompted the child to "try using a full sentence," while avoiding the use of pronouns so as not to prime the participant. If the child still did not produce a response with pronouns, the experimenter continued to the next trial. This protocol was repeated for each of the six objects. Objects were asked in the same order for all trials to ease administration of the experiment ${ }^{1}$, and experimenters were instructed to ask the questions with consistent voice volume and intonation throughout the session and across conditions.

Once the session was complete, the child was thanked for their participation and invited to select a small toy as a thank you gift. The experimenter then provided parents with a debriefing form and thanked them for their participation.

Transcription and Coding-During the session, the experimenter who was not working directly with the child transcribed the child's responses. The experimenter also indicated whether the child needed to be prompted to answer in a full sentence. After data collection was complete, transcriptions for all available audio data were checked against the recordings for accuracy by a second research assistant. Next, a group of two independent coders coded participants' responses, blind to condition. Each response was coded into one of six categories to fully capture the range of provided responses: (1) generic you, including variations such as your, you're; (2) first person singular pronouns, which for parsimony are referred to as Iresponses but included I, my, mine, me, and contractions such as I'm; (3) we, including variations such as we're; (4) on-topic responses without coded pronouns (i.e., responses that did not contain $I$, we, or generic you, e.g., "Ride bikes outside"; non-generic uses of you were included here); (5) off-topic responses (e.g., "Having chicken..."); or (6) no answer (i.e. the child simply did not respond). A given response could be coded in multiple categories (e.g. "I don't color, but you draw with them" would be coded as both " $I$ " and "generic you").

\footnotetext{
${ }^{1}$ For three participants, two of the items were asked in the incorrect order.
} 
Reliability between coders was high, $\kappa=.98$ and a third coder resolved discrepancies. Once discrepancies were resolved, each participant received a frequency score for each of the six categories; for example, a child who use generic you in two responses and provided responses without personal pronouns in four responses would receive a score of 2 for generic you, 4 for on-topic responses without coded pronouns, and 0s for all other categories. To ease interpretation, frequencies were then calculated as a percentage of the six trials (e.g., if a participant used generic you in two of the six trials, they would receive a $33 \%$ for generic you usage).

Six children at 3-4 years, eight children at 5-6 years, and three children at 7-10 years were missing audio files, either because their parent did not provide permission for the session to be audio recorded or due to human or technical error. Given that one experimenter wrote down children's responses during the session, the data from these participants are included in the analyses reported below.

\section{Results}

Of central interest was participants' use of generic you and $I$ across the six trials; Table 1 provides information on the frequency with which participants provided all coded responses by condition. We were also interested in how the type and frequency of responses might differ by age. Given that each participant received two scores, one for generic you and one for $I$, we conducted a mixed-factorial ANOVA, with Condition (2: Norms vs. Preferences) and Age Group (3: 3-4, 5-6, 7-10) as the between-subjects factors and Response Type (2: You vs. I) as the within-subjects factor. The two dependent variables were the percentage of trials containing generic you and the percentage of trials containing $I$. These scores are independent, in that each participant could have provided more than one response code per trial. The patterns of results reported below were also obtained when the data were analyzed using non-parametric tests. ${ }^{2}$

As predicted, there was a significant Condition $\times$ Response Type interaction, $F(1,123)=$ $86.71, p<.001, \eta_{\mathrm{p}}^{2}=.41$. Planned pairwise comparisons revealed that participants used generic you significantly more in the Norms condition $(M=52.62 \%)$ than in the Preferences condition $(M=10.58 \%), p<.001$. In contrast, participants used $I$ significantly more in the Preferences condition $(M=52.75 \%)$ than in the Norms condition $(M=9.20 \%), p<.001$. There was no main effect of response, $F(1,123)=.02, p=.89, \eta_{\mathrm{p}}^{2}=.00$, indicating that neither generic you nor $I$ was more frequent overall. There was also no main effect of condition, $F(1,123)=.06, p=.81, \eta_{\mathrm{p}}^{2}=.00$, indicating that providing a codable pronoun (collapsing over generic you and $I$ ) did not vary as a function of condition. However, there

\footnotetext{
${ }^{2}$ The Mann-Whitney test for non-parametric distributions does not allow for within-subject models; thus, we examined the effect of condition on generic you and Iseparately. Condition on generic you: Mean RankNorms $=82.50$, Mean RankPrefs $=47.23, U=$ 942.50, $|\mathrm{z}|=5.86, p<.001$. Condition on I: Mean Rank Norms $=47.90$, Mean RankPrefs $=82.37, U=3,191.50,|z|=5.74, p<.001$. These results remained significant when examining the effect of condition on each age group separately. [3-4 year olds]: Condition on generic you: Mean RankNorms $=27.12$, Mean RankPrefs $=20.45, U=197.00,|z|=1.94, p=.053$; Condition on I: Mean RankNorms $=20.56$, Mean RankPrefs $=27.91, U=361.00,|\mathrm{z}|=2.18, p=.03$; [5-6 year olds]: Condition on generic you: Mean Rank Norms $=$ 29.90, Mean RankPrefs $=17.85, U=134.50,|\mathrm{z}|=3.19, p=.001$; Condition on I: Mean RankNorms $=18.50$, Mean RankPrefs $=$ 29.74, $U=408.00,|z|=3.13, p=.002 ;$ [7-10 year olds]: Condition $\rightarrow$ generic you: Mean Rank Norms $=26.59$, Mean RankPrefs $=$ 10.76, $U=14.50,|z|=4.97, p<.001$; Condition on $I$ : Mean RankNorms $=9.72$, Mean RankPrefs $=24.97, U=284.50,|z|=4.58, p<$. 001.
} 
was a significant main effect of age group, $F(2,123)=22.75, p<.001, \eta_{\mathrm{p}}{ }^{2}=.27$, and a significant Condition $\times$ Age Group $\times$ Response Type interaction, $F(2,123)=9.49, p=.001$, $\eta_{\mathrm{p}}^{2}=.13$.

To understand the nature of this interaction, we performed planned contrasts within each age group. As Figure 1 illustrates, children in every age group produced you more often in the Norms condition than the Preferences condition: $3-4$ years: $F(1,123)=4.35, p=.039, \eta_{\mathrm{p}}{ }^{2}$ $=.03 ; 5-6$ years: $F(1,123)=11.91, p=.001, \eta_{\mathrm{p}}{ }^{2}=.09 ; 7-10$ years: $F(1,123)=52.19, p<$. $001, \eta_{\mathrm{p}}{ }^{2}=.30$. Conversely, children in each age group produced $I$ more often in the Preferences condition than the Norms condition: $3-4$ years: $F(1,123)=10.31, p=.002, \eta_{\mathrm{p}}{ }^{2}$ $=.08 ; 5-6$ years: $F(1,123)=13.16, p<.001, \eta_{\mathrm{p}}^{2}=.10 ; 7-10$ years: $F(1,123)=41.35, p<$. $001, \eta_{\mathrm{p}}{ }^{2}=.25$. Both of these patterns were evident even among 3-4 year-olds. However, as age increased, so did the magnitude of these effects.

Post-hoc analyses were conducted to explore the basis of the aforementioned age effects. There were no significant differences between age groups in how frequently the unpredicted response was produced: $p \mathrm{~s}>.39$ regarding production of $I$ in response to the Norm questions; $p s>.20$ regarding production of you in response to the Preference questions. However, there were several significant age differences in how frequently the predicted response was produced. Specifically, for the Norm questions, 7-10 year-olds produced you significantly more than 3-4 and 5-6 year-olds, $p s \leq .001$, and 5-6 year olds produced generic you significantly more than 3-4 year olds, $p=.022$. Similarly, for the Preference questions, 7-10 year-olds produced $I$ significantly more than 3-4 and 5-6 year-olds, $p$ s $<$. 001. These results suggest that the youngest children are not being less discriminating than older children in their use of these pronouns. Instead, the major difference is that the predicted use of these pronouns is lower for children 3-6 years of age than children 7-10 years of age.

\section{Study 2}

The results of Study 1 suggest that children conceptualize descriptive norms as general and preferences as individual early in development. Study 2 sought to extend these findings in three ways to determine the robustness of the effect: (1) to examine whether children similarly are more likely to reach a generic interpretation of you for questions that ask about prescriptive (as opposed to descriptive) norms, than for questions that ask about preferences; (2) to examine these uses in natural language conversations between children and their parents; (3) to focus on the age group that was the youngest in Study 1. To examine these questions, parents conversed with their children about both preferences and prescriptive norms using a within-subject design. We predicted that children would be more likely to use generic you in response to questions that asked about prescriptive norms as opposed to questions about preferences.

\section{Method}

Participants-Twenty-nine parent-child dyads were recruited from a small Midwestern city. One dyad was excluded because the parent did not provide any codable questions regarding prescriptive norms (see below), leaving a sample of 28 . The final sample of 28 
children ranged in age from 2.13 to $4.94(M=3.90, S D=0.92)$ (18 boys, 10 girls; 25 White/ Caucasian, 2 Black/African American, and 1 Biracial). Parents included 24 mothers and 4 fathers.

Materials-Materials consisted of 24 items divided into two sets (Set A and Set B) of 12 items each, matched on superordinate category (animals, objects, foods) and valence (positive, negative) (see Table 2). The items were presented in two books, one focused on prescriptive norms (i.e. "What should you do? What shouldn't you do?") and one focused on preferences (i.e. "What do you like? What don't you like?"). The assignment of set (i.e., Set A, Set B) to book (i.e., Norms vs. Preferences) was fully counterbalanced, with each participant receiving one of each book, yielding a 2 (Item List A vs. Item List B) $\times 2$ (Book: Norms vs. Preferences) repeated-measures design. Items in the book were presented in a quasi-random order, with negative and positive items interspersed at regular intervals across the four books.

Procedure-The study took place in an on-campus, child-friendly laboratory. After parents provided informed consent and granted permission for the session to be video recorded, the experimenter obtained assent from the child. Dyads were then brought into the room where they would be completing the main task, and were seated on a comfortable couch. The experimenter asked the parent to read both books to their child, in a given order (counterbalanced across participants). Finally, parents were instructed to read the directions in the book before they began talking with their child. The interaction was video recorded through a one-way mirror.

In the Norms book (entitled "Do's and Don'ts"), the instructions read, "Please talk with your child about appropriate behaviors: what you or your child should or shouldn't do." On each page, a full-color photograph of an item appeared on a white background accompanied by the text, "What should you do? What shouldn't you do?" In the Preferences book (entitled "Smiles and Frowns"), the instructions read, "Please talk with your child about preferences: what you or your child likes or doesn't like." Each item appeared on a separate page and was accompanied by the text, "What do you like? What don't you like?" After parents finished reading and discussing both books with their child, they were thanked for their participation and given compensation. Children were given a small toy as thanks.

Transcription and Coding-All sessions were transcribed verbatim from the video recordings and checked by a second transcriber. A priori, we were interested only in children's responses to questions containing the pronoun you that asked either about prescriptive norms or preferences. To identify such questions (henceforth referred to as "target questions"), the transcribed files were prepared in two steps: First, to ensure blind coding, files were filtered so that only the parents' utterances were visible. Next, coders read each parent line and identified which utterances met all of the following inclusion criteria: (1) question in the form of "what" (e.g., "What should you do?"; "What do you like about kittens?"); (2) inclusion of either "like/don't like" or "should/shouldn't"; note that questions with only "do" (e.g., "What do you do with Xs?") were not included; (3) inclusion of the pronoun "you"; (4) for those questions that mentioned an item, the item had to be generic (e.g., "What do you like about dogs?", not "What do you like about this dog?") and needed 
to refer to one of the items contained in the books. If a parent question did not match the condition they were in (e.g., a "like" question in the Norms condition), this was excluded; this happened only once. Given the objective nature of the coding, only $20 \%$ of transcripts were prepared by a second independent coder; reliability across this sample was high, $\kappa=$. 98.

The next phase of the coding involved coding children's responses to the questions identified in the first phase. To ensure blindness to condition, each file was filtered so that only the line immediately following each of the identified parent questions was visible. Two independent coders coded each of these lines into four categories: (1) Uncodable (i.e., no child response, non-speech response [e.g., gesture], unintelligible, and off-task [e.g., "I have to go to the bathroom"]); (2) Generic you (including your, you're, etc.); (3) I (including me, my, mine, I've, etc.); or (4) Other (e.g. responses that did not fall into previous three categories; e.g., non-generic you, we, "I don't know"). A given line could be coded into more than one category. The first three transcripts were used for training purposes; reliability among the remaining 25 transcripts was high, $\boldsymbol{\kappa}=.94$, and discrepancies were resolved by a third coder.

\section{Results}

On average, parents generated 17.14 target questions in the Prescriptive Norms condition and 15.32 target questions in the Preferences condition. Each child's generic you and $I$ responses were divided by the total number of target questions that the child's parent had asked and then converted to a percentage score, separately for the Norms and the Preferences conditions, yielding four scores per child (see Table 3 for descriptive statistics on the four types of responses that were coded). A 2 (Condition: Norms vs. Preferences) $\times 2$ (Response Type: Generic you vs. I) $\times 2$ (Order: Norms first vs. Preferences first) ANOVA was conducted, with both Condition and Response Type as within-subjects factors, and Order as a between-subjects factor.

As predicted, we obtained a significant Condition $\times$ Response Type interaction, $F(1,26)=$ $18.90, p<.001, \eta_{\mathrm{p}}{ }^{2}=.42$. Planned contrasts indicated that children produced generic you more often in response to Norms questions $(M=12.50)$ than Preference questions $(M=$ 2.74), $F(1,26)=4.35, p=.047, \eta_{\mathrm{p}}^{2}=.14$. Children also produced $I$ more often in response to Preference questions $(M=26.84)$ than Norms questions $(M=3.82), F(1,26)=41.73, p<$. $001, \eta_{\mathrm{p}}^{2}=.62$. There was also a main effect of Condition, $F(1,26)=14.27, p=.001, \eta_{\mathrm{p}}{ }^{2}=$. 35 , indicating that children were more likely to provide a codable pronoun (collapsing over generic you and $I$ ) in the Preferences condition than in the Norms condition. Finally, we obtained a main effect of Response, $F(1,26)=14.29, p=.001, \eta_{\mathrm{p}}{ }^{2}=.36$; $I$ was more common than generic you, collapsing over Condition. There were no significant effects involving order: $p s \geq .07$. The pattern of results reported above was also obtained when the data were analyzed using non-parametric tests. ${ }^{3}$

\footnotetext{
${ }^{3}$ Given the fully within-subject design of Study 2, the Friedman test for non-parametric repeated measures ANOVAs was conducted. There was a significant difference in generic you production in the Norms vs. Preferences condition, $\chi^{2}(1)=4.00, p=.046$. There was also a significant difference in $I$ production in response to the Norms vs. Preferences questions, $\chi^{2}(1)=18.62, p<.001$.
} 


\section{General Discussion}

These studies examined children's interpretation of the pronoun you in sentence frames expressing either norms ("What do you do with Xs?", "What should you do with Xs?") or preferences ("What do you like to do with Xs?", "What do you like about Xs?"). Three patterns of results were possible: Children could have consistently interpreted you as canonical, which would have been reflected in uniformly high rates of responding with $I$ across conditions. Alternatively, children could have learned that you may express generic ideas, without having learned to differentiate where such uses are appropriate, which would have been reflected by indiscriminate use of you across conditions. Finally, children could have recognized that generic interpretations of you are more appropriate in response to questions that asked about norms, whereas canonical interpretations are more appropriate to express preferences. It is this last pattern of findings that we obtained. This pattern was robust in every age group studied, including the youngest (age 2-4 years). Thus, children have command of both canonical and generic you at a remarkably young age. These findings are striking given that the test questions all used the same pronoun ("you") and that the contexts of use were so similar (varying only in "do" or "should/shouldn't do" vs. "like to do").

The developmental patterns further support an early grasp of generic you as normative. In Study 1 , there were increases in the rates at which children produced the predicted responses (you for norms, I for preferences), but there were not decreases in the unpredicted responses (you for preferences, $I$ for norms). Thus, at no age did children indicate a purely canonical interpretation of you. Rather, these age differences indicate that the older children more consistently followed the instructions to provide full sentences in response to the test questions. Furthermore, Study 2 focused exclusively on the youngest age group and found the same pattern of results.

These findings demonstrate that different sentence frames (cueing norms vs. preferences) elicit different uses of you. An interesting extension for future research would be to cue children to think in terms of either norms or preferences and then ask them identical questions in both conditions (e.g., "What do you do at the playground?"). If children used you more often when cued to think about norms and used Imore often when cued to think about preferences, this would further demonstrate that context alone can modulate children's interpretation.

Another important question to address is whether using generic you in normative contexts elicits different expectations than using canonical you or I in normative contexts (i.e., the reverse process of what these studies addressed)? Can varying the language that children hear encourage a more vs. less normative stance? These questions have potentially important implications for the role of language in guiding children's interactions with and learning about their social world. Given children's sensitivity to the generic/normative distinction in our task, we would hypothesize that the reverse implications would also appear early in development. For example, perhaps generic uses of you, by implying a broader, more inclusive norm, would be a more effective means of getting a child to comply with a request 
than other expressive forms, or would be a powerful tool with which to communicate lessons about the social world (e.g., "You can't always get what you want").

Study 2 focused on children's use of generic you in response to their parents' questions. In future research it would also be important to examine the contexts in which parents spontaneously provide information using generic you when speaking with their children. For example, recent research with adults suggests that generic you is evoked when reflecting on emotionally difficult past events. For adults, the normative use of you includes the provision of timeless truths or "lessons learned," as an effective means of distancing oneself from, and moving past, a stressful situation (Orvell et al., 2017). It would be interesting to see if parents, and even young children, likewise use generic you in this way.

Another intriguing question is how broadly a norm is expected to apply. Whereas some norms apply only to specific contexts (e.g., in this classroom, backpacks belong in one's cubby), other norms apply broadly (e.g., in general, it's wrong to hit someone). Does generic you imply that a norm extends to all types of people, just to people within one's social group(s), or to different types of groups depending on the context? Do such expectations vary with the child's age? Does generic you imply greater breadth than other generic expressions, such as generic nouns (e.g., "children")? We suspect that the answers to these questions may vary as a function of speaker and context (e.g., a teacher's statement may be viewed as specific to the classroom context, whereas a parent's statement may be viewed as more generally true), though this remains an empirical question.

Note that personal pronouns in and of themselves convey no content, but rather are canonically characterized as deictics - essentially equivalent to finger points. Importantly, we see that when the pronoun you is used in a context where it can be interpreted generically, that is, when it broadens in meaning to refer to people in general, its use is not simply to point out a group of people but rather to link tightly to norms and to communicate an expectation for how things are (Study 1) or should be (Study 2). Thus, a normative interpretation is added to you when it shifts in meaning from non-generic to generic. An important further question is whether this same pattern applies in other languages. The personal pronoun you has a dual usage as a generic form in multiple languages, including Chinese, Danish, Dutch, English, German, Gulf Arabic, Hindi, and Italian (De Hoop \& Tarenskeen, 2015; Jensen, 2009; Kitagawa \& Lehrer, 1990; Siewierska, 2004). We would expect generic you to have normative implications in all of these languages, but this remains an open empirical question.

\section{Conclusions}

Although norms can be conveyed non-linguistically, for example, by means of modeling, rituals, or corrective feedback (Kenward, Karlsson, \& Persson, 2011; Keupp, Behne, \& Rakoczy, 2013), they can also be conveyed via language. Indeed, not only is language an especially powerful and efficient means of communicating norms, but Gibbard (1990, p. 787) has proposed that doing so may be one of its key biological functions: "A crucial function of talk ... is to adjust the terms of social cooperation. Talk helps adjust the norms we accept together, and the norms we accept, in turn, have much to do with the ways we 
interact." It is perhaps not surprising, then, that children are exquisitely sensitive to subtle shifts in how language is deployed when expressing preferences versus norms.

\section{Acknowledgments}

We thank the children and families who participated in this research. We also thank Elizabeth Baxter and Serena Saake for their help with data collection and Elizabeth Uribe and the research assistants of the University of Michigan Conceptual Development and Emotion and Self-Control Labs who were involved in this project for their help with transcription and coding. Finally, we thank the Living Laboratory ${ }^{\circledR}$ at the Ann Arbor Hands-On Museum and the Museum of Natural History, where this research was conducted, and Dr. Craig Smith and Margaret Echelbarger for their help and support.

Funding: This research was supported in part through grants from the John Templeton Foundation (348747) and the NSF (BCS-1509457) to Kross and NICHD (HD-36043) to Gelman.

\section{References}

Andersen, E. Speaking with style: The sociolinguistic skills of children. London: Routledge; 2014.

Bear A, Knobe J. Normality: Part descriptive, part prescriptive. Cognition. in press.

Berry R. You could say that: the generic second-person pronoun in modern English. English Today. 2009; 25(3):29-34.

Bolinger D. To catch a metaphor: You as norm. American Speech. 1979:194-209.

Carlson, GN., Pelletier, FJ., editors. The generic book. Chicago: University of Chicago Press; 1995.

Casler K, Terziyan T, Greene K. Toddlers view artifact function normatively. Cognitive Development. 2009; 24:240-247.

Cialdini R, Trost M. Social influence: Social norms, conformity and compliance. The Handbook of Social Psychology. 1998; 2:151-192.

Cialdini RB, Kallgren CA, Reno RR. A focus theory of normative conduct: A theoretical refinement and reevaluation of the role of norms in human behavior. Advances in Experimental Social Psychology. 1991; 24:201-234.

Cimpian A, Markman EM. Preschool children's use of cues to generic meaning. Cognition. 2008; 107(1):19-53. [PubMed: 17765216]

Cimpian A, Markman EM. Information learned from generic language becomes central to children's biological concepts: Evidence from their open-ended explanations. Cognition. 2009; 113:14-25. [PubMed: 19674739]

De Hoop H, Tarenskeen S. It's all about you in Dutch. Journal of Pragmatics. 2015; 88:163-175.

Evans KE, Demuth K. Individual differences in pronoun reversal: Evidence from two longitudinal case studies. Journal of Child Language. 2012; 39:162-191. [PubMed: 21669013]

Fenson L, Dale PS, Reznick JS, Bates E, Thal DJ, Pethick SJ, Stiles J. Variability in early communicative development. Monographs of the Society for Research in Child Development. 1994; 59(5):v-173.

Fisher AV, Sloutsky VM. When induction meets memory: Evidence for gradual transition from similarity-based to category-based induction. Child Development. 2005; 76(3):583-597. [PubMed: 15892780]

Gelman, SA., Coley, JD., Rosengren, KS., Hartman, E., Pappas, A. Beyond labeling: The role of maternal input in the acquisition of richly structured categories. Monographs of the Society for Research in Child Development; 1998. p. i-157.

Gelman SA, Goetz PJ, Sarnecka BW, Flukes J. Generic language in parent-child conversations. Language Learning and Development. 2008; 4(1):1-31. [PubMed: 21765807]

Gelman SA, Raman L. Preschool children use linguistic form class and pragmatic cues to interpret generics. Child Development. 2003; 74(1):308-325. [PubMed: 12625452]

Gelman SA, Tardif T. A cross-linguistic comparison of generic noun phrases in English and Mandarin. Cognition. 1998; 66(3):215-248. [PubMed: 9689770] 
Gelman SA, Ware E, Kleinberg F. Effects of generic language on category content and structure. Cognitive Psychology. 2010; 61(3):273-301. [PubMed: 20638053]

Gelman SA, Ware EA, Kleinberg F, Manczak EM, Stilwell SM. Individual differences in children's and parents' generic language. Child Development. 2014; 85(3):924-940. [PubMed: 24266531]

Gelman SA, Ware EA, Manczak EM, Graham SA. Children's sensitivity to the knowledge expressed in pedagogical and nonpedagogical contexts. Developmental Psychology. 2013; 49(3):491-504. [PubMed: 22468565]

Gibbard A. Norms, discussion, and ritual: evolutionary puzzles. Ethics. 1990; 100(4):787-802.

Göckeritz S, Schmidt MH, Tomasello M. Young children's creation and transmission of social norms. Cognitive Development. 2014; 30:81-95.

Graham SA, Gelman SA, Clarke J. Generics license 30-month-olds' inferences about the atypical properties of novel kinds. Developmental Psychology. 2016; 52(9):1353-1362. [PubMed: 27505699]

Hollander MA, Gelman SA, Raman L. Generic language and judgments about category membership: Can generics highlight properties as central? Language and Cognitive Processes. 2009; 24(4):481505. [PubMed: 25620828]

Hyman Staels E. The indefinite you. English Studies: A Journal of English Language and Literature. 2004; 85(2):161-176.

Jensen TJ. Generic variation? Developments in use of generic pronouns in late 20th century spoken Danish. Acta Linguistica Hafniensia. 2009; 41(1):83-115.

Kalish CW. Generalizing norms and preferences within social categories and individuals. Developmental Psychology. 2012; 48(4):1133-1143. [PubMed: 22103303]

Kenward B, Karlsson M, Persson J. Over-imitation is better explained by norm learning than by distorted causal learning. Proceedings of the Royal Society of London B: Biological Sciences. 2011; 278(1709):1239-1246.

Keupp S, Behne T, Rakoczy H. Why do children over-imitate? Normativity is crucial. Journal of Experimental Child Psychology. 2013; 116(2):392-406. [PubMed: 23933292]

Kitagawa C, Lehrer A. Impersonal uses of personal pronouns. Journal of Pragmatics. 1990; 14(5):739_ 759.

Knobe J, Prasada S, Newman GE. Dual character concepts and the normative dimension of conceptual representation. Cognition. 2013; 127(2):242-257. [PubMed: 23454798]

Laberge, S., Sankoff, G. Anything you can do. In: Givón, T., editor. Discourse and syntax. New York: Academic Press; 1979. p. 419-440.

Leslie SJ. Generics oversimplified. Noûs. 2015; 49(1):28-54.

Mulkay MJ. Norms and ideology in science. Social Science Information. 1976; 15(4-5):637-656.

Myers G, Lampropoulou S. Impersonal you and stance-taking in social research interviews. Journal of Pragmatics. 2012; 44(10):1206-1218.

Orvell A, Kross E, Gelman SA. How “you” makes meaning. Science. 2017; 355(6331):1299-1302. [PubMed: 28336666]

Oshima-Takane Y, Takane Y, Shultz TR. The learning of first and second person pronouns in English: Network models and analysis. Journal of Child Language. 1999; 26(3):545-575. [PubMed: 10603696]

Papafragou A. On generics. UCL Working Papers on Linguistics. 1996; 8:165-198.

Pennycook A. The politics of pronouns. ELT Journal. 1994; 48(2):173-178.

Prasada S, Dillingham EM. Principled and statistical connections in common sense conception. Cognition. 2006; 99(1):73-112. [PubMed: 16443448]

Prasada S, Dillingham EM. Representation of principled connections: A window onto the formal aspect of common sense conception. Cognitive Science. 2009; 33(3):401-448. [PubMed: 21585476]

Rakoczy H, Schmidt MH. The early ontogeny of social norms. Child Development Perspectives. 2013; 7(1):17-21. 
Rakoczy H, Warneken F, Tomasello M. The sources of normativity: young children's awareness of the normative structure of games. Developmental Psychology. 2008; 44(3):875-881. [PubMed: 18473651]

Rakoczy H, Warneken F, Tomasello M. Young children's selective learning of rule games from reliable and unreliable models. Cognitive Development. 2009; 24(1):61-69.

Repacholi BM, Gopnik A. Early reasoning about desires: evidence from 14-and 18-month-olds. Developmental Psychology. 1997; 33(1):12-21. [PubMed: 9050386]

Rhodes M. Children's explanations as a window into their intuitive theories of the social world. Cognitive Science. 2014; 38(8):1687-1697. [PubMed: 25052813]

Rhodes M, Leslie SJ, Tworek CM. Cultural transmission of social essentialism. Proceedings of the National Academy of Sciences. 2012; 109(34):13526-13531.

Roberts SO, Gelman SA, Ho A. So it is, so it shall be: Group regularities license children's prescriptive judgments. Cognitive Science. in press.

Siegel DR, Callanan MA. Artifacts as conventional objects. Journal of Cognition and Development. 2007; 8:183-203.

Siewierska, A. Person. New York: Cambridge University Press; 2004.

Tworek CM, Cimpian A. Why do people tend to infer "ought" from "is"? The role of biases in explanation. Psychological Science. 2016; 27(8):1109-1122. [PubMed: 27485133]

Wales, K. Personal pronouns in present-day English. Cambridge University Press; 1996.

Wellman HM, Liu D. Scaling of theory-of-mind tasks. Child Development. 2004; 75(2):523-541. [PubMed: 15056204]

Wodak D, Leslie SJ, Rhodes M. What a loaded generalization: Generics and social cognition. Philosophy Compass. 2015; 10(9):625-635. 


\section{Highlights}

- The distinction between norms and preferences directs young children's interpretation and use of everyday language.

- Children as young as 2-4 years old interpret you as generic in normative sentence frames and as canonical in preference sentence frames.

- Children as young as 2-4 years old use generic you ("you" that refers to people in general) to express norms, and use $I$ to express personal preferences. 


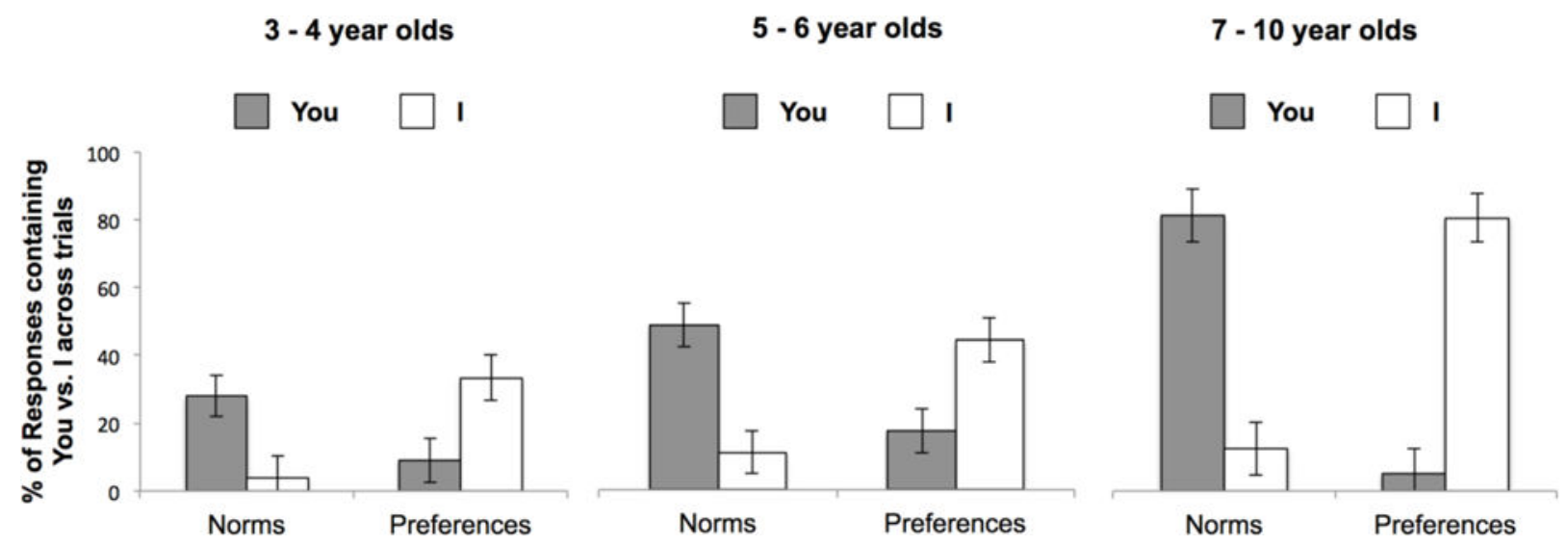

Figure 1.

Mean percentage of responses including generic you vs. $I$ across trials by condition. The $x$ axis indicates whether participants produced you or $I$ in their response. The $y$ axis represents how often you vs. I was used as a percentage of the six trials that were presented. Higher rates of generic you (vs. I) in response the Norms prompt indicate that you was interpreted as generic, whereas higher rates of $I$ (vs. you) in response the Preference prompt indicate that you was interpreted as canonical. 


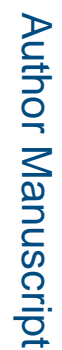

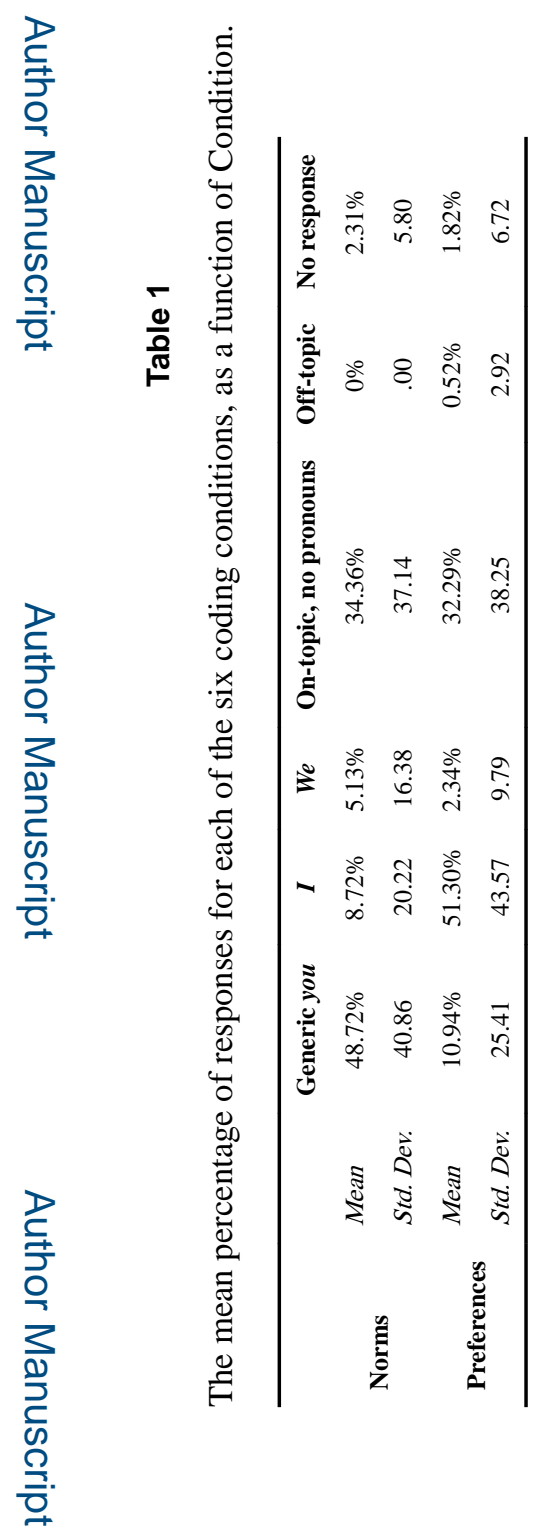

J Exp Child Psychol. Author manuscript; available in PMC 2019 January 01. 


\section{Table 2}

\begin{tabular}{|c|c|c|c|}
\hline & Animals & Objects & Foods \\
\hline \multirow{4}{*}{ Set A } & Fish & Ball & Apple \\
\hline & Puppy & Bike & Broccoli \\
\hline & Skunk & Crayon & Cupcake \\
\hline & Spider & Stove & Spaghetti \\
\hline \multirow{4}{*}{ Set B } & Bird & Book & Orange \\
\hline & Kitten & Puzzle & Spinach \\
\hline & Snake & $\mathrm{TV}$ & Ice cream \\
\hline & Bee & Knife & Pizza \\
\hline
\end{tabular}



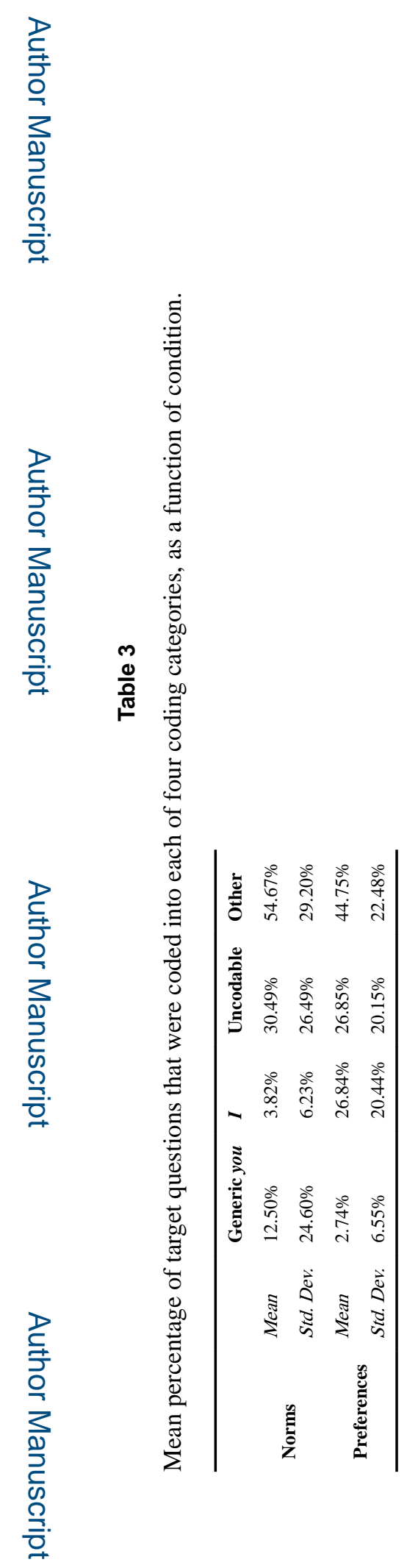

J Exp Child Psychol. Author manuscript; available in PMC 2019 January 01. 